\title{
Peptide Phage Display for Discovery of Novel Biomarkers for Imaging and Therapy of Cell Subpopulations in Ovarian Cancer
}

Mette Soendergaard ${ }^{1}$, Jessica R Newton-Northup ${ }^{1}$, Mark O Palmier ${ }^{1}$ and Susan L Deutscher ${ }^{1,2 *}$

${ }^{1}$ University of Missouri, Department of Biochemistry, Columbia, MO 65211

${ }^{2}$ Harry S Truman Veterans Memorial Hospital, Columbia, MO, 65201

\begin{abstract}
Ovarian cancer is a very aggressive disease that is mostly asymptomatic at early onset. Approximately $85 \%$ of patients are diagnosed at late-stage disease, which greatly compromises full recovery. Standard detection methods include measurement of the ovarian cancer biomarker CA-125. However, CA-125 is associated with false positive diagnosis and is largely limited to late-stage disease. As a result, there is a great need to discover new biomarkers and develop novel detection and imaging methods for ovarian cancer. Patients with ovarian cancer often respond to initial chemotherapy but most will succumb to recurrent disease. Such poor prognosis is associated with a drug resistant subpopulation of cancer cells with stem-like properties known as cancer stem cells (CSC). Traditional chemotherapy fails to target CSC, and it is widely accepted that this process leads to the recurrence of more aggressive tumors. Therefore, it is essential to discover new ovarian CSC biomarkers and develop therapies that specifically target this subpopulation. Bacteriophage (phage) display technology allows identification of high affinity peptides by screening of peptide libraries against cellular targets. The large amount of unique peptides in a library facilitates high throughput selections both in vivo and in vitro. Here we discuss how phage display can be utilized to discover novel peptides with high binding affinity for normal ovarian cancer cells and ovarian CSC. Such peptides may be radiolabeled and employed in SPECT and PET imaging as well as in therapeutic settings. Further, both phage and phage display derived peptides can be employed in identification of targeted antigens and novel ovarian cancer biomarkers using mass spectrometry analysis. Such biomarkers may be utilized in diagnosis and in identification and selection of ovarian cancer subpopulations.
\end{abstract}

Keywords: Ovarian cancer; Phage display; Peptide; Cancer stem cells

\section{Ovarian Cancer}

Ovarian cancer is the fifth leading cause of cancer deaths in women and is the most lethal of the gynecological malignancies [1,2]. In 2011, it is estimated that 21,990 women in the US will be diagnosed with ovarian cancer and that 15,450 women will die from the disease [3]. Ovarian cancer is an aggressive disease that is characterized by a symptom free onset and early metastasis. Neoplastic cells rapidly invade surrounding tissues through the peritoneal fluid and metastasize predominantly as fluid containing ascites in the peritoneal cavity [4,5]. Approximately $85 \%$ of patients are diagnosed at late-stage disease, which leads to significantly decreased five-year survival rates of merely $30-45 \%[1,2]$. Furthermore, ovarian cancer often develops resistance to therapy after initial platinum-based treatment, and even though most patients respond to chemotherapy, the majority relapse within 18 months and succumb to disease [1,6-8].

Ovarian cancer is a very heterogeneous disease that comprises three major types: epithelial, stromal and germ cell of which the former represents about $95 \%$ of diagnosed cases. Epithelial ovarian cancer can be further divided into eight subtypes: endometrioid, mucinous, serous, clear cell, transitional, squamous, undifferentiated and mixed epithelial that each exhibit different molecular and morphological characteristics [7,9-11]. In addition to the large diversity among ovarian cancer subtypes the largely asymptomatic early stages of the disease complicates diagnosis and treatment. At present, standard detection methods include measurement of the serum tumor-marker CA-125 (Mucin 16) as well as pelvic ultrasonography [12-14]. However, CA125 levels are often negligible in early-stage disease and elevated in only $80 \%$ of advanced stage ovarian cancer. In addition, false positive CA-125 levels are common for a range of other conditions such as endometriosis, inflammatory disease and other cancers, and the method is, therefore, often not sufficient to be diagnostic. Ultrasonography of the pelvis is often used in combination with CA-125 levels to diagnose ovarian cancer, nevertheless, early stage tumors are difficult to detect using this method, and false-positives often arise due to benign cysts related to overactive ovaries [12-16]. Several attempts have been made to find novel serum tumor markers of early-stage ovarian cancer, including measurements of soluble epidermal growth factor receptor (sEGFR) [17,18], soluble cytokeratin 19 fragments [19], serum human kallikreins [20-23] and serum vascular endothelial growth factor (VEGF) [24,25]. However, most of these biomarkers are limited to advanced stage or metastatic disease and are, therefore, not sufficiently sensitive for early-stage ovarian cancer screening and diagnosis. For these reasons, it is necessary to develop new detection methods for both early- and advanced stage ovarian cancer.

Treatment of ovarian cancer most often includes cytoreductive surgery followed by a range of chemotherapeutic therapies dependent on disease stage [1,6]. Combinations of the drugs paclitaxel, carboplatin, cisplatin and cyclophosphamide are often used to treat both early and late-stage disease following surgery and most patients respond to this treatment. Nonetheless, the majority of patients relapse within 18 months with therapy resistant disease, which cause median

*Corresponding author: Susan L Deutscher, Ph.D., University of Missouri, Department of Biochemistry, Columbia, MO 65211, Tel: 573-882-2454; Fax: 573884-4597; E-mail: deutschers@missouri.edu

Received September 30, 2011; Accepted November 15, 2011; Published November 19, 2011

Citation: Soendergaard M, Newton-Northup JR, Palmier MO, Deutscher SL (2011) Peptide Phage Display for Discovery of Novel Biomarkers for Imaging and Therapy of Cell Subpopulations in Ovarian Cancer. J Mol Biomark Diagn S2:004. doi:10.4172/2155-9929.S2-004

Copyright: (c) 2011 Soendergaard M, et al. This is an open-access article distributed under the terms of the Creative Commons Attribution License, which permits unrestricted use, distribution, and reproduction in any medium, provided the original author and source are credited 
Citation: Soendergaard M, Newton-Northup JR, Palmier MO, Deutscher SL (2011) Peptide Phage Display for Discovery of Novel Biomarkers for Imaging and Therapy of Cell Subpopulations in Ovarian Cancer. J Mol Biomark Diagn S2:004. doi:10.4172/2155-9929.S2-004

survival times as low as 24 months post diagnosis [1,6-8,26]. Such poor prognosis seems to result from chemotherapy treatment that targets only the bulk of the tumor cells and fails to target the more aggressive cancer initiating cells (CIC) or cancer stem cells (CSC). This process most likely causes the occurrence of more aggressive tumors that are resistant to therapy (Figure 1) [27-29].

\section{Ovarian Cancer Stem Cells}

Cancer stem cells were first observed in acute myeloid leukemia [30] and have since been discovered in several solid tumors including breast, prostate, melanoma and ovarian cancer [31-34]. Ovarian CSC were first isolated by Bapat and co-workers (2005) from ascites in a patient with advanced disease. The cells were shown to display the stem cell surface markers CD44 (hyaluronic acid receptor) and CD117 (ckit) as well as the intracellular stem cell markers Nestin, Oct-4 and Nanog [31,35]. Later, ovarian CSC were found to express aldehyde dehydrogenase (ALDH) and the cell surface marker CD133 (prominin-1), [36,37]. The expression of these CSC biomarkers has been correlated with increased resistance to chemotherapeutic drugs. In fact, CD44 positive cells have been associated with resistance to the chemotherapeutic drugs carboplatin and paclitaxel [35], and CD133 expression has been correlated with resistance to cisplatin [37]. A subpopulation of cells expressing the biomarkers CD44 and CD117 from primary human ovarian tumors were shown to form floating spheroids in culture when grown under stem cell conditions (serum free, EGF, bFGF and insulin). The spheroids visually resembled spheroids found in ovarian cancer ascites $[28,31]$ as well as cultured spheroids from breast and neural tissue stem cells [38,39]. Later CD133 and ALDH positive cells from ovarian epithelial carcinomas were also shown to form spheroids in culture and in addition cause larger and more rapid tumors to form compared to $\mathrm{CD} 133$ and ALDH negative cells [36]. The aggressiveness of CSC is also evident from their ability to initiate tumor formation. In fact, as few as 100 dissociated spheroid cells have been found to cause full establishment of tumors in mice, whereas up to $10^{5}$ of unselected cells were unable to initiate tumor growth [40]. In addition, these cells were able to serial propagate and established heterogeneous tumors with original phenotype after several rounds of propagation. The chemoresistance of CSC is associated with expression of the membrane efflux transporter ABCG2 [27,41,42], which has been found to be upregulated in CSC from primary ovarian tumors and in both murine and human ovarian cancer cell lines $[27,40,43]$. Increased drug-efflux in CSC has been based on their ability to efflux the lipophillic dye Hoechst $33342[27,28,44]$. Side populations of mouse ovarian cancer cells exhibiting reduced Hoechst 33342 staining have been shown to increase tumorigenesis in nude mice [28]. A side population has also been observed in the human ovarian cancer cell line SK-OV-3, where approximately $10 \%$ of the cells showed reduced Hoechst 33342 staining [27]. Taking these results together it seems likely that the development of molecules that target CSC may hold the key to increase the therapeutic efficiency for ovarian cancer. So far most studies have focused on drug candidates that inhibit cellular signaling pathways [45], however, it may be necessary to target CSC cell surface biomarkers that are independent of the ABCG2 drug-efflux system. Cancer stem cell targeting radiolabeled peptides may provide an efficient method to eradicate the CSC subpopulation.

\section{Bacteriophage Display}

Bacteriophage (phage) display technology was first developed by Dr. George Smith in 1985 [46]. The technology involves the expression of combinatorial peptide libraries on filamentous phage coat proteins. Every phage in a library expresses a unique peptide, and this diversity can be used to screen phage libraries against in vitro or in vivo targets
[46-48]. A typical phage display library contains up to $10^{9}$ different phage clones, each displaying a random type of peptide. The large number of different peptides in a library makes phage display a high throughput method for affinity selections. The best characterized of the filamentous phage is the Ff class, which include the M13, fd and $\mathrm{f} 1$ viruses that are structurally very similar and $98 \%$ identical at the DNA level. Structurally, the Ff class of phage resembles a flexible rod, which measures $\sim 0.9 \mu \mathrm{m}$ in length and $\sim 65 \AA$ in diameter. The Ff genome is approximately $6.4 \mathrm{~kb}$ large (ssDNA) and encodes 11 proteins of which five are structural. Two of these are coat protein III (cpIII) and coat protein VIII (cpVIII). Both are surface exposed and are, for this reason, used to display the foreign peptides on the phage surface [46-48]. One of the most common phage display vector systems is the fUSE5 vector, which displays up to five copies of the peptides on cpIII. Another commonly used phage display vector is the f88-4 vector system, which displays several hundred copies of the peptide on cpVIII. Experimentally, the phage display library is most often screened against an antigen of interest using several rounds of affinity selection, elution and amplification. The amplification step is relatively straight forward in that the Ff class of phage infects gram-negative bacteria, such as $E$. coli, and uses the bacterial machinery to produce progeny phage, which are released without lysis through the bacterial plasma membrane [46$51,52,2,53]$. Phage display technology has been employed to discover novel peptides that bind cancer cells. For example, RGD-peptides have been developed that target the tumor vasculature by binding to av $\beta 3$-integrin (vitronectin receptor) [54,55]. The SGRSA peptide has been found to have high binding affinity to urokinase plasminogen activator (uPA) [56] and the peptide CGNSNPKSC to bind to gastric cancer endothelium [57]. Our laboratory has developed a number of peptides that target cancer cells. Among these are the peptide KCCYSL that binds to the ErbB-2 (HER2/neu) receptor [58,59], which is a member of the EGF receptor family and is upregulated in both ovarian and breast carcinoma. The HER2/neu oncogene is overexpressed in approximately $15-30 \%$ of ovarian carcinomas and is associated with an increased risk of progression and death, especially among women diagnosed with stage I and II ovarian carcinoma [60,61]. In addition, the peptides IAGLATPGWSHWLAL and ANTPCGPYTHDCPVKR were selected for binding to the prostate carcinoma cell line PC-3
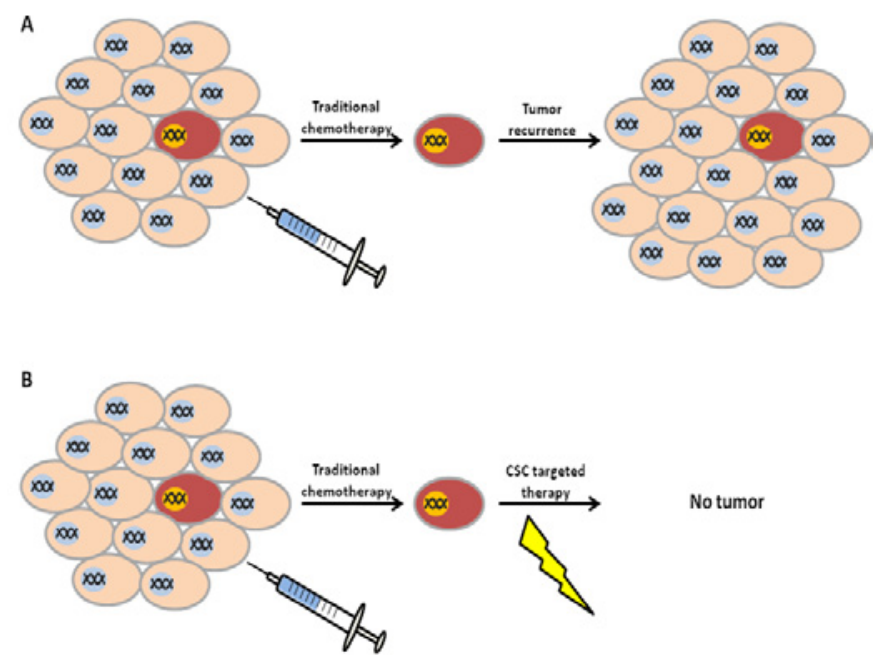

Figure 1: Traditional and CSC targeted therapies in ovarian cancer. A) Traditional chemotherapy fails to target CSC, which allows successive regrowth of the tumor. B) CSC targeted therapy in combination with traditional chemotherapy eradicates both tumor populations and hinder tumor recurrence. 
[62,63] and galectin-3, respectively [64-67]. Furthermore, a number of peptides have been developed that bind to the Thomsen-Friedenreich (TF) carbohydrate antigen, which is present on approximately $90 \%$ of human carcinoma cells and is involved in cell adhesion and migration [68-71]. Most of these tumor targeting peptides have been developed to function as imaging and/or therapeutic agents of human cancers. Radiolabeling of tumor targeting peptides provides an effective method of eradicating cancer cells as well as imaging tumors in vivo using technologies such as single photon emission computed tomography (SPECT) and positron emission tomography (PET).

\section{New Ovarian Cancer Cell Targeting Peptides}

In order to efficiently select ovarian targeting peptides with high affinity for a tumor and desirable pharmacokinetics, it is important to initially pre-clear the phage display library from peptide motifs that bind to normal vasculature. This may be accomplished by intravenously injecting non-tumor bearing mice with an appropriate volume of $>$ $10^{14}$ virions $/ \mathrm{mL}$ of phage library followed by a 15 minute incubation time. Mice are then sacrificed, the blood harvested and unbound phage amplified and purified for further rounds of selection. For in vivo selections against ovarian carcinoma, our laboratory has used SCID mice carrying SK-OV-3 human carcinoma cell xenografted tumors. After injection of pre-cleared phage library tumor bound phage may be eluted after excision by using detergents. Amplified and purified phage may then be used for further rounds of in vivo/ex vivo selections $[53,62,72]$. Selected phage clones may be additionally analyzed for their binding affinity by micropanning experiments in which phage are incubated with different carcinoma and normal cell lines. Phage binding affinity may be evaluated by comparing the number of infectious units (TU/mL) between the cancerous and normal cell lines. In order to analyze the binding affinities of peptides outside of the phage environment, biotinylated or radiolabeled peptides may be synthesized and used in in vitro/in vivo binding studies [62,73].

In vivo selection of ovarian carcinoma specific peptides can be an inefficient procedure. One potential barrier is the presence of many tissue types within the tumor, endothelial cells, connective tissue, etc. Determination/selection of the targeted tissue for each selected peptide can be difficult when the in vivo milieu is so complex. Thus, an additional round of ex vivo selection may be added to try and select peptides that bind directly to ovarian carcinoma tumor cells. For this purpose $\mathrm{MACS}^{\circledR}$ technology may be utilized to separate ovarian carcinoma tumor cells from undesired tissue types. In order to avoid non-specific binding of phage, the phage may first be selected negatively against the MACS column and streptavidin labeled magnetic beads. Cells from excised human ovarian carcinoma tumors from xenografted mice may then be labeled with a mixture of biotinylated antibodies against known ovarian cancer biomarkers and then bound to streptavidin magnetic beads. Cells can then be loaded onto a MACS separation column and incubated with phage from previous selection rounds. Bound phage can be eluted from cells using detergents and subsequently amplified and purified. A good candidate for a known ovarian cancer biomarker includes the epithelial cell adhesion molecule (EpCAm; CD326), which is overexpressed in a variety of carcinomas, as well as normal epithelial tissues. Overexpression is present in $~ 70 \%$ of ovarian carcinomas and is significantly related to a decreased overall survival [74]. Another known ovarian cancer marker is CA-125 (Mucin 16) that is an ovarian cancer-associated antigen, and is, as described above, used as a serum biomarker for ovarian cancer. CA-125 is the extracellular domain (ECD) of the cell surface protein MUC16 and levels of the protein are known to increase with disease stage [75].
ErbB-2 (HER2/neu) is a member of the EGF receptor family and is also overexpressed in both ovarian and breast carcinoma. The HER2/ neu oncogene is overexpressed in approximately $15-30 \%$ of ovarian carcinomas and is associated with an increased risk of progression and death, especially among women diagnosed with stage I and II ovarian carcinoma, which makes it an interesting cell surface biomarker for ovarian cancer $[60,61]$

\section{New Ovarian Cancer Stem Cell (CSC) Targeting Peptides}

Selection of phage display derived peptides with high binding affinity for ovarian CSC is complicated by the fact that CSC only represents a small percentage of the entire tumor mass [28,31]. Thus CSC must initially be selected and separated from the remaining regular cancer cells. This may be done, as described above, utilizing MACS technology using antibodies against known ovarian CSC biomarkers such as CD44, CD117 and CD133 [31,35-37]. Alternatively, CSC can be selected by growing ovarian cancer cells in stem cell appropriate medium $[35,43]$. Successful separation of CSC may be visualized by formation of spheroids in culture and staining with antibodies against ovarian CSC biomarkers. It may be advisable to further select CSC using flow cytometry cell sorting using antibodies against the known ovarian CSC biomarkers [28,43]. Further, normal cancer cells may be separated during this process and used for negative selections.

Even though the nature of CSC prevents selection of phage display derived peptides in vivo, pre-clearing of the phage display library may still be performed in non-tumor bearing mice as described above. In the early stages of selections, it is also important to consider the tumor microenvironment in that CSC comprise only a small part of the tumor bulk $[28,31]$. Thus in order to ensure specific binding, the library may be further pre-cleared against normal ovarian cancer cells before selecting for binding to CSC. Such a selection should be done ex vivo using cultured normal tumor tissue, and may be performed by utilizing MACS $^{\circledR}$ technology as previously described. However, if the normal cancer cells have already been separated from CSC using flow cytometry, it will be sufficient to use non-labeled cells in suspension. Experimentally, it may be difficult to obtain large numbers of ovarian CSC, and it can be essential to cultivate CSC in appropriate stem cell medium $[28,31,35,43]$ after separation from the tumor bulk. Cultured ovarian CSC form three dimensional spheroids in stem cell medium and it may be necessary to dissociate the cells to a singlecell suspension for the phage display selection. For the selection, the MACS $^{\circledR}$ technology may be employed by labeling ovarian CSC with antibodies against the known biomarkers CD44, CD117 and CD133 [31,35-37]. Alternatively, CSC in suspension or grown on plates can be used instead. It is important to note that cells grown under such conditions must be tested for the presence of ovarian CSC biomarkers before selection in order to ensure that cells have not differentiated. Furthermore, it is imperative to use a large number ( $>10^{13}$ virions) of phage in the first selection rounds in order to guarantee high diversity of phage clones [76]. After initial rounds the amount of phage may be lowered to increase selection stringency. As described above, selected phage clones may be further analyzed for their binding affinity by micropanning experiments in which phage are incubated with normal ovarian cancer cells and ovarian CSC. Once high binding clones have been identified, biotinylated or radiolabeled peptides can be synthesized and analyzed for their tumor targeting abilities [62,73]. Peptides with high binding affinity for CSC will most likely not be applicable as imaging agents due to the low percentage of CSC in a tumor. However, the chemotherapeutic abilities of such radiolabeled peptides can be evaluated in in vivo therapy studies using xenografted mice [77-80]. 
Citation: Soendergaard M, Newton-Northup JR, Palmier MO, Deutscher SL (2011) Peptide Phage Display for Discovery of Novel Biomarkers for Imaging and Therapy of Cell Subpopulations in Ovarian Cancer. J Mol Biomark Diagn S2:004. doi:10.4172/2155-9929.S2-004

Most likely, radiolabeled peptides for CSC tumor therapy must be combined with other forms of chemotherapy, such as more traditional platinum based drugs, in order to eradicate all cells in a tumor [81]. Thus, in a mouse therapy study it may be necessary to compare the therapeutic effects of drugs such as carboplatin and paclitaxel, which are standard in current ovarian cancer treatment, the effects of the radiolabeled peptide as well as a combined approach.

\section{Radiolabeled Peptides for Tumor Imaging and Therapy}

While antibodies and their fragments are by far the most used cancer targeting imaging and therapeutic agents [82], peptides exhibit better biodistribution properties. Antibodies often cause drug resistance, have long biodistribution times and clear through the hepatobiliary system, whereas peptides show low immunogenicity, rapid bloodclearance and are excreted in the urine [83-87]. High kidney uptake has, however, been observed with peptides, which poses a problem in regard to tumor imaging near the kidney and with toxicity caused by accumulation of therapeutic radiolabeled peptides [82,86-88]. Thus lowering renal uptake is important and may be done by changing parts of the peptide sequence, trying different radionuclides and chelates or by co-administration of lysine or arginine $[86,87,89]$.

Radiolabeling of tumor targeting peptides affords a proficient way of imaging in vivo using technologies such as single photon emission computed tomography (SPECT) and positron emission tomography (PET). SPECT was one of the first imaging modalities used clinically and is today widely employed in cancer imaging. Both ${ }^{99 \mathrm{~m} T c}$ [90] $(6 \mathrm{~h}$ half-life) and ${ }^{111}$ In (2.8 day half-life) are frequently used in SPECT [91]. PET is an emerging imaging technique that offers certain advantages compared to SPECT in regard to sensitivity as well as quantitation [92]. The $\beta^{+}$-emitting tracer fluorine-18 2-deoxy-2-fluoro-D-glucose $\left({ }^{18} \mathrm{~F}-\mathrm{FDG}\right)$ is a commonly used PET tracer for imaging processes with increased glucose metabolism [93]. However, the uptake of ${ }^{18} \mathrm{~F}-\mathrm{FDG}$ is not increased in all cells and has not shown great promise in early stage ovarian cancer diagnosis [94]. Therefore, alternative PET tracers are being developed that target antigens on cancer cells [92,95]. Octreotide is an eight amino acid cyclized peptide that has been successfully developed for imaging of somatostatin receptor positive tumors in humans when labeled with ${ }^{111} \mathrm{In}$ - diethylenetriaminepentaacetic acid (DTPA) [96]. The $\alpha$-Melanocyte Stimulating Hocmone ( $\alpha-\mathrm{MSH}$ ) analog has been conjugated with the chelator 1,4,7,10-tetraazacyclodecane1,4,7,10-tetraacetic acid (DOTA) and labeled with ${ }^{64} \mathrm{Cu},{ }^{86} \mathrm{Y}$ and ${ }^{68} \mathrm{Ga}$ for PET imaging of melanoma [97,98]. Our laboratory has identified peptides that bind ovarian, breast, and prostate tumors $[59,63,64,73,99,100]$. The phage display selected peptide KCCYSL against ErbB-2 has been radiolabeled with ${ }^{111} \mathrm{In}$ and used for SPECT/ CT imaging of human MDA-MB-435 breast and OV-CAR-3 and SKOV-3 ovarian xenografted tumors (Figure 2) $[58,59,73,99]$.

Whereas many cancer therapeutic agents function by binding and inhibiting receptors or other molecules involved in the progression of cancer, radiolabeling of peptides provides a method to target and eradicate cancer cells independent of peptide function and intracellular signaling pathways. Labeling peptides with $\beta$-particle emitting radioisotopes are being used for targeted tumor radiotherapy and offer advantages in regard to varying degrees of energy emission. Highenergy $\beta$-emitters such as ${ }^{90} \mathrm{Y}$ ( 2.7 day half-life $)$ are appropriate for the treatment of large tumor burdens, whereas medium and lower-energy $\beta$-emitters, such as ${ }^{177} \mathrm{Lu}$ (6.7 day half-life) may be more suitable for treating smaller tumors, residual tumor or metastatic deposits found in ovarian cancer $[101,102]$. One example of a radiolabeled peptide being developed for tumor therapy is the $\alpha$-MSH peptide analog, CCMSH, which targets melanoma cells. The $\alpha-\mathrm{MSH}$ analog has been conjugated with the chelator DOTA and labeled with ${ }^{212} \mathrm{~Pb}$ and used for melanoma therapy studies in mice. The treatment showed significantly increased survival rates in which $45 \%$ of the mice receiving the highest dose of radiation survived the study disease-free $[78,79]$.

These results demonstrate that radiolabeled peptides offer great promise as both cancer imaging and therapeutic agents. Peptides that target early stage ovarian cancer cells could be developed into diagnostic imaging/therapeutic agents. Furthermore, peptides may be developed that target tumor subpopulations such as ovarian CSC.

\section{Identification of Antigens Targeted by Selected Phage Displayed Peptides}

Both phage and peptides can be used in formats that allow identification of targeted antigens. Previous studies have employed cross-linking of phage or selected peptides to antigens as a means to identify peptide targets [103,104]. Kelly et al. have employed photolinker and biotin labeled phage to bind and capture target antigens on the cell surface. After binding and cross-linking, cell lysates were incubated with streptavidin beads. Antigens were eluted by reversing the crosslink and subsequently used for SDS-PAGE followed by tryptic digest and mass spectrometry analysis [104]. However, these techniques can suffer from lack of specificity due to the use of multiple cross-linkers and the large size of filamentous phage. In addition, phage are known to aggregate and exhibit high non-specific binding to cells, which may result in identification of numerous irrelevant proteins via mass spectrometry.

Alternatively, uniquely designed immobilized fusion proteins may offer a powerful means of isolating specific targets of phage display selected peptide sequences. For example a recombinant fusion protein containing a phage display selected peptide can be developed to aid the antigen capture process. Such a fusion protein may contain an $\mathrm{N}$-terminal protein, such as thioredoxin, which acts as a soluble fusion partner linked to a matrix specific binder and a series of protease cleavage sites. Our laboratory has adapted a thioredoxin fusion protein that remains soluble in E. coli cytosol and can be purified, during immobilization on S-protein sepharose (Figure 3). Thioredoxin will be removed by cleavage with a protease, leaving the phage display peptide still bound to the S-protein sepharose. The immobilized

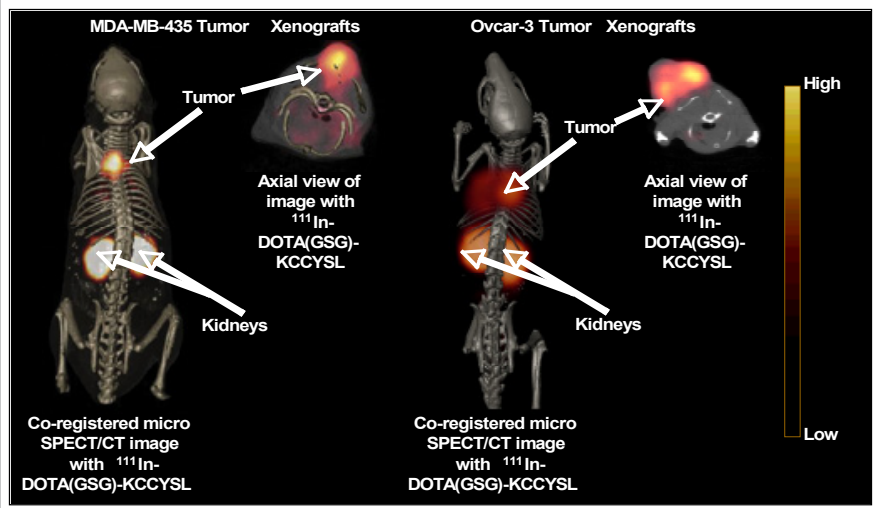

Figure 2: SPECT imaging of ${ }^{111} \mathrm{In}-\mathrm{DOTA}(\mathrm{GSG})-\mathrm{KCCYSL}$ ErbB-2 targeting peptide in MDA-MB-435 breast and OV-CAR-3 ovarian tumor bearing SCID mice. MDA-MB-435 breast and OVCAR ovarian tumor xenografted SCID mice were injected in the tail vein with $11.1 \mathrm{MBq}$ of ${ }^{111} \mathrm{In}$-DOTA(GSG)-KCCYSL peptide or ${ }^{111}$ In-DOTA)GSG)-KYLCSC scrambled peptide and imaged by microSPECT/CT one hour later. 
Citation: Soendergaard M, Newton-Northup JR, Palmier MO, Deutscher SL (2011) Peptide Phage Display for Discovery of Novel Biomarkers for Imaging and Therapy of Cell Subpopulations in Ovarian Cancer. J Mol Biomark Diagn S2:004. doi:10.4172/2155-9929.S2-004

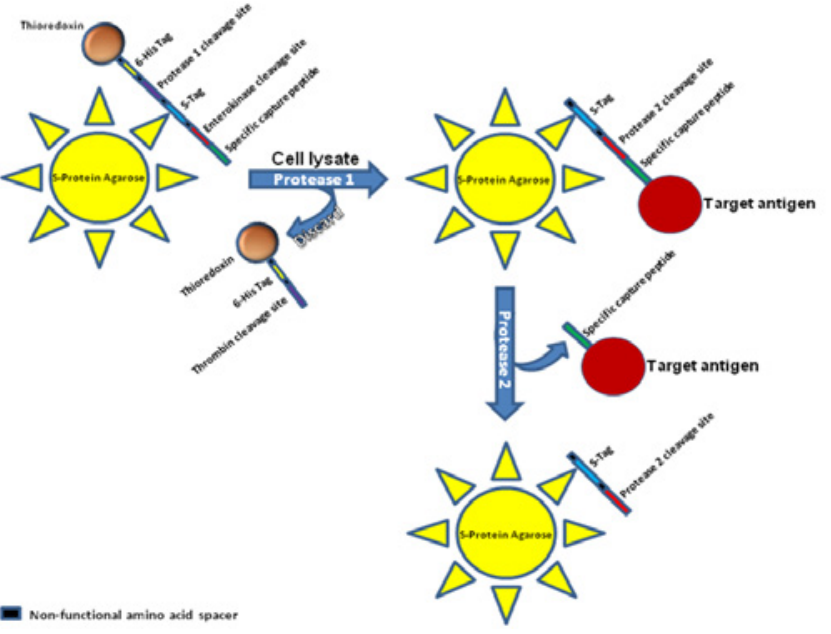

Figure 3: Isolation of bacteriophage targets using immobilized heterofunctional thioredoxin fusion proteins. Thioredoxin acts as a solubilizer and allows the complex to bind to the column matrix in aqueous solution. After cleavage of thioredoxin, cell lysate is added to let the phage display derived peptide capture target antigens, which are eluted from the column by protease cleavage.

peptide complex will then be accessible for binding to its target protein. The phage display derived peptide and its target antigen may then be released from the S-protein sepharose by cleavage with a second protease. Once bound target proteins from cell lysates have been obtained they may be analyzed by $2 \mathrm{D}$ gel electrophoresis and identified by proteomic methodologies.

\section{Acknowledgements}

This work was supported by a Ment Review Award form the Veterans Administration (SLD).

\section{References}

1. Aletti GD, Gallenberg MM, Cliby WA, Jatoi A, Hartmann LC (2007) Current Management Strategies for Ovarian Cancer. Mayo Clinic Proceedings 82: 751 770 .

2. Pecorelli S, Favalli G, Zigliani L, Odicino F (2003) Cancer in women International journal of gynaecology and obstetrics: the official organ of the International Federation of Gynaecology and Obstetrics 82: 369-379.

3. American Cancer Society CFaF (2011).

4. Eltabbakh GH (2004) Recent advances in the management of women with ovarian cancer. Minerva Ginecol 56: 81-89.

5. Sonoda $Y$ (2004) Management of early ovarian cancer. Oncology (Williston Park) 18: 343-356; discussion 358, 361-362

6. Ozols RF (2005) Treatment goals in ovarian cancer. International Journal of Gynecological Cancer 15: 3-11.

7. Hennessy BT, Coleman RL, Markman M (2009) Ovarian cancer. The Lancet 374: 1371-1382.

8. Piccart MJ, Bertelsen K, James K, Cassidy J, Mangioni C et al. (2000) Randomized intergroup trial of cisplatin-paclitaxel versus cisplatincyclophosphamide in women with advanced epithelial ovarian cancer: threeyear results. J Natl Cancer Inst 92: 699-708.

9. Tavassoli FADP (2003) Pathology and Genetics. Tumours of the Breast and female Genital Organs. International Agency for Research on Cancer and World Health Organization. IARC Press, Lyon France.

10. Godwin AK, Testa JR, Hamilton TC (1993) The biology of ovarian cancer development. Cancer 71: 530-536.

11. Ness RB, Cottreau C (1999) Possible role of ovarian epithelial inflammation in ovarian cancer. J Natl Cancer Inst 91: 1459-1467.
12. Zurawski VR, Orjaseter $H$, Andersen A, Jellum $E$ (1988) Elevated serum CA 125 levels prior to diagnosis of ovarian neoplasia: relevance for early detection of ovarian cancer. Int J Cancer 42: 677-680.

13. Neesham D (2007) Ovarian cancer screening. Australian Family Physician 36 126-128.

14. Eltabbakh GH, Belinson JL, Kennedy AW, Gupta M, Webster K et al. (1997) Serum CA-125 measurements $>65 \mathrm{U} / \mathrm{mL}$. Clinical value. J Reprod Med 42 617-624.

15. Bast RC, Hennessy B, Mills GB (2009) The biology of ovarian cancer: new opportunities for translation. Nat Rev Cancer 9: 415-428.

16. Cannistra SA (2004) Cancer of the ovary. N Engl J Med 351: 2519-2529.

17. Baron AT, Boardman CH, Lafky JM, Rademaker A, Liu D et al. (2005) Soluble epidermal growth factor receptor (sEGFR) [corrected] and cancer antigen 125 (CA125) as screening and diagnostic tests for epithelial ovarian cancer. Cancer Epidemiol Biomarkers Prev 14: 306-318.

18. Baron AT, Cora EM, Lafky JM, Boardman CH, Buenafe MC et al. (2003) Soluble epidermal growth factor receptor (sEGFR/sErbB1) as a potential risk screening, and diagnostic serum biomarker of epithelial ovarian cancer. Cancer Epidemiol Biomarkers Prev 12: 103-113.

19. Gadducci A, Ferdeghini M, Cosio S, Fanucchi A, Cristofani R et al. (2001) The clinical relevance of serum CYFRA 21-1 assay in patients with ovarian cancer. Int J Gynecol Cancer 11: 277-282.

20. Luo LY, Katsaros D, Scorilas A, Fracchioli S, Bellino R et al. (2003) The serum concentration of human kallikrein 10 represents a novel biomarker for ovarian cancer diagnosis and prognosis. Cancer Res 63: 807-811.

21. Shan SJ, Scorilas A, Katsaros D, Rigault de la Longrais I, Massobrio M et al. (2006) Unfavorable prognostic value of human kallikrein 7 quantified by ELISA in ovarian cancer cytosols. Clin Chem 52: 1879-1886.

22. Borgono CA, Grass L, Soosaipillai A, Yousef GM, Petraki CD et al. (2003) Human kallikrein 14: a new potential biomarker for ovarian and breast cancer. Cancer Res 63: 9032-9041.

23. Yousef GM, Polymeris ME, Grass L, Soosaipillai A, Chan PC et al. (2003) Human kallikrein 5: a potential novel serum biomarker for breast and ovarian cancer. Cancer Res 63: 3958-3965.

24. Cooper BC, Ritchie JM, Broghammer CL, Coffin J, Sorosky JI et al. (2002) Preoperative serum vascular endothelial growth factor levels: significance in ovarian cancer. Clin Cancer Res 8: 3193-3197.

25. Hefler LA, Zeillinger R, Grimm C, Sood AK, Cheng WF et al. (2006) Preoperative serum vascular endothelial growth factor as a prognostic parameter in ovarian cancer. Gynecol Oncol 103: 512-517.

26. Dean M, Fojo T, Bates S (2005) Tumour stem cells and drug resistance. Na Rev Cancer 5: 275-284.

27. Hirschmann-Jax C, Foster AE, Wulf GG, Nuchtern JG, Jax TW et al. (2004) A distinct "side population" of cells with high drug efflux capacity in human tumor cells. Proceedings of the National Academy of Sciences of the United States of America 101: 14228-14233.

28. Szotek PP, Pieretti-Vanmarcke R, Masiakos PT, Dinulescu DM, Connolly $\mathrm{D}$ et al. (2006) Ovarian cancer side population defines cells with stem celllike characteristics and Mullerian Inhibiting Substance responsiveness Proceedings of the National Academy of Sciences 103: 11154-11159.

29. Diehn M, Clarke MF (2006) Cancer stem cells and radiotherapy: new insights into tumor radioresistance. J Natl Cancer Inst 98: 1755-1757.

30. Bonnet D, Dick JE (1997) Human acute myeloid leukemia is organized as a hierarchy that originates from a primitive hematopoietic cell. Nat Med 3: 730 737.

31. Bapat SA, Mali AM, Koppikar CB, Kurrey NK (2005) Stem and ProgenitorLike Cells Contribute to the Aggressive Behavior of Human Epithelial Ovarian Cancer. Cancer Research 65: 3025-3029.

32. Al-Haji M, Wicha MS, Benito-Hernandez A, Morrison SJ, Clarke MF (2003) Prospective identification of tumorigenic breast cancer cells. Proc Natl Acad Sci U S A 100: 3983-3988.

33. Fang D, Nguyen TK, Leishear K, Finko R, Kulp AN et al. (2005) A tumorigenic subpopulation with stem cell properties in melanomas. Cancer Res 65: 93289337. 
Citation: Soendergaard M, Newton-Northup JR, Palmier MO, Deutscher SL (2011) Peptide Phage Display for Discovery of Novel Biomarkers for Imaging and Therapy of Cell Subpopulations in Ovarian Cancer. J Mol Biomark Diagn S2:004. doi:10.4172/2155-9929.S2-004

Page 6 of 8

34. Patrawala L, Calhoun T, Schneider-Broussard R, Li H, Bhatia B et al. (2006) Highly purified CD44+ prostate cancer cells from xenograft human tumors are enriched in tumorigenic and metastatic progenitor cells. Oncogene 25: 16961708.

35. Alvero AB CR, Fu HH, Montagna M, Schwartz PE, Rutherford T, et al. (2009) Molecular phenotyping of human ovarian cancer stem cells unravels the mechanisms for repair and chemoresistance. Cell Cycle 8: 158-166.

36. Kryczek I, Liu S, Roh M, Vatan L, Szeliga W et al. (2011) Expression of aldehyde dehydrogenase and CD133 defines ovarian cancer stem cells. Int J Cancer 130:29-39.

37. Baba T, Convery PA, Matsumura N, Whitaker RS, Kondoh E et al. (2009) Epigenetic regulation of CD133 and tumorigenicity of CD133+ ovarian cancer cells. Oncogene 28: 209-218.

38. Locke M, Heywood M, Fawell S, Mackenzie IC (2005) Retention of intrinsic stem cell hierarchies in carcinoma-derived cell lines. Cancer Res 65: 89448950.

39. Vescovi AL, Reynolds BA, Fraser DD, Weiss S (1993) bFGF regulates the proliferative fate of unipotent (neuronal) and bipotent (neuronal/astroglial) EGFgenerated CNS progenitor cells. Neuron 11: 951-966.

40. Zhang S, Balch C, Chan MW, Lai H-C, Matei D et al. (2008) Identification and Characterization of Ovarian Cancer-Initiating Cells from Primary Human Tumors. Cancer Research 68: 4311-4320.

41. Sharom FJ (2008) ABC multidrug transporters: structure, function and role in chemoresistance. Pharmacogenomics 9: 105-127.

42. Derda R, Tang SK, Li SC, Ng S, Matochko W et al. (2011) Diversity of phagedisplayed libraries of peptides during panning and amplification. Molecules 16 : 1776-1803.

43. Shi M, Jiao J, Lu W, Ye F, Ma D et al. (2010) Identification of cancer stem cell-like cells from human epithelial ovarian carcinoma cell line. Cellular and Molecular Life Sciences 67:3915-3925.

44. Clarke MF, Dick JE, Dirks PB, Eaves CJ, Jamieson CH et al. (2006) Cancer stem cells--perspectives on current status and future directions: AACR Workshop on cancer stem cells. Cancer Res 66: 9339-9344.

45. Hombach-Klonisch S, Paranjothy T, Wiechec E, Pocar P, Mustafa T et al. (2008) Cancer stem cells as targets for cancer therapy: selected cancers as examples. Arch Immunol Ther Exp (Warsz) 56: 165-180.

46. Smith GP (1985) Filamentous fusion phage: novel expression vectors that display cloned antigens on the virion surface. Science 228: 1315-1317.

47. Smith GP, Petrenko VA (1997) Phage Display. Chem Rev 97: 391-410.

48. Marvin DA (1998) Filamentous phage structure, infection and assembly. Curr Opin Struct Biol 8: 150-158.

49. Gray CW, Brown RS, Marvin DA (1981) Adsorption complex of filamentous fd virus. J Mol Biol 146: 621-627.

50. Armstrong J, Perham RN, Walker JE (1981) Domain structure of bacteriophage fd adsorption protein. FEBS Lett 135: 167-172.

51. Crissman JW, Smith GP (1984) Gene-III protein of filamentous phages: evidence for a carboxyl-terminal domain with a role in morphogenesis. Virology 132: $445-455$.

52. Sidhu SS (2005) Phage display in biotechnology and drug discovery. (CRC Press/Taylor \& Francis).

53. Newton JR, Deutscher SL (2009) In vivo bacteriophage display for the discovery of novel peptide-based tumor-targeting agents. Methods Mol Biol 504: 275-290.

54. Arap W, Pasqualini R, Ruoslahti E (1998) Cancer treatment by targeted drug delivery to tumor vasculature in a mouse model. Science 279: 377-380.

55. Chen X, Sievers E, Hou Y, Park R, Tohme M et al. (2005) Integrin alpha v beta 3-targeted imaging of lung cancer. Neoplasia 7: 271-279.

56. Ploug M, Ostergaard S, Gardsvoll H, Kovalski K, Holst-Hansen C et al. (2001) Peptide-derived antagonists of the urokinase receptor. affinity maturation by combinatorial chemistry, identification of functional epitopes, and inhibitory effect on cancer cell intravasation. Biochemistry 40: 12157-12168.

57. Hui X, Han Y, Liang S, Liu Z, Liu J et al. (2008) Specific targeting of the vasculature of gastric cancer by a new tumor-homing peptide CGNSNPKSC $J$ Control Release 131: 86-93.

58. Karasseva NG, Glinsky VV, Chen NX, Komatireddy R, Quinn TP (2002) Identification and characterization of peptides that bind human ErbB-2 selected from a bacteriophage display library. J Protein Chem 21: 287-296.

59. Kumar SR, Quinn TP, Deutscher SL (2007) Evaluation of an 111ln-radiolabeled peptide as a targeting and imaging agent for ErbB-2 receptor expressing breast carcinomas. Clin Cancer Res 13: 6070-6079.

60. Beerli RR, Graus-Porta D, Woods-Cook K, Chen X, Yarden Y et al. (1995) Neu differentiation factor activation of ErbB-3 and ErbB-4 is cell specific and displays a differential requirement for ErbB-2. Mol Cell Biol 15: 6496-6505.

61. Hartmann F, Horak EM, Cho C, Lupu R, Bolen JB et al. (1997) Effects of the tyrosine-kinase inhibitor geldanamycin on ligand-induced Her-2/neu activation, receptor expression and proliferation of Her-2-positive malignant cell lines. Int J Cancer 70: 221-229.

62. Newton JR, Kelly KA, Mahmood U, Weissleder R, Deutscher SL (2006) In vivo selection of phage for the optical imaging of $\mathrm{PC}-3$ human prostate carcinoma in mice. Neoplasia 8: 772-780.

63. Newton-Northup JR, Figueroa SD, Quinn TP, Deutscher SL (2009) Bifunctional phage-based pretargeted imaging of human prostate carcinoma. Nucl Med Biol 36: $789-800$.

64. Deutscher SL, Figueroa SD, Kumar SR (2009) Tumor targeting and SPEC imaging properties of an (111)In-labeled galectin-3 binding peptide in prostate carcinoma. Nucl Med Biol 36: 137-146.

65. Kumar DSL (2006) Galectin-3-Targeting Peptides as Novel In Vivo tumorImaging and Targeting Agents. Tumor Microvasculature Environment AACR Meeting. Florence, Italy.

66. Zou J, Glinsky VV, Landon LA, Matthews L, Deutscher SL (2005) Peptides specific to the galectin-3 carbohydrate recognition domain inhibit metastasisassociated cancer cell adhesion. Carcinogenesis 26: 309-318.

67. Kumar SR, Deutscher SL (2008) 111/n-labeled galectin-3-targeting peptide as a SPECT agent for imaging breast tumors. J Nucl Med 49: 796-803.

68. Matarrese P, Fusco O, Tinari N, Natoli C, Liu FT et al. (2000) Galectin-3 overexpression protects from apoptosis by improving cell adhesion properties. Int J Cancer 85: 545-554.

69. Glinsky VV, Glinsky GV, Rittenhouse-Olson K, Huflejt ME, Glinskii OV et al (2001) The role of Thomsen-Friedenreich antigen in adhesion of human breas and prostate cancer cells to the endothelium. Cancer Res 61: 4851-4857.

70. Landon LA, Peletskaya EN, Glinsky VV, Karasseva N, Quinn TP et al. (2003) Combinatorial evolution of high-affinity peptides that bind to the ThomsenFriedenreich carcinoma antigen. J Protein Chem 22: 193-204.

71. Peletskaya EN, Glinsky VV, Glinsky GV, Deutscher SL, Quinn TP (1997) Characterization of peptides that bind the tumor-associated ThomsenFriedenreich antigen selected from bacteriophage display libraries. Journal of Molecular Biology 270: 374-384.

72. Newton-Northup JR, Figueroa SD, Deutscher SL (2010) Streamlined In Vivo Selection and Screening of Human Prostate Carcinoma Avid Phage Particles for Development of Peptide Based In Vivo Tumor Imaging Agents. Comb Chem High Throughput Screen 14: 9-21

73. Kumar SR, Gallazzi FA, Ferdani R, Anderson CJ, Quinn TP et al. (2010) In vitro and in vivo evaluation of Cu-radiolabeled KCCYSL peptides for targeting epidermal growth factor receptor-2 in breast carcinomas. Cancer Biother Radiopharm 25: 693-703

74. Kim JH, Herlyn D, Wong KK, Park DC, Schorge JO et al. (2003) Identification of epithelial cell adhesion molecule autoantibody in patients with ovarian cancer Clin Cancer Res 9: 4782-4791.

75. Chauhan SC, Vinayek N, Maher DM, Bell MC, Dunham KA et al. (2007) Combined staining of TAG-72, MUC1, and CA125 improves labeling sensitivity in ovarian cancer: antigens for multi-targeted antibody-guided therapy. J Histochem Cytochem 55: 867-875.

76. Smith GP, Scott JK (1993) Libraries of peptides and proteins displayed on filamentous phage. Methods Enzymol 217: 228-257.

77. Miao Y, Hoffman TJ, Quinn TP (2005) Tumor-targeting properties of 90Y- and 177 Lu-labeled alpha-melanocyte stimulating hormone peptide analogues in murine melanoma model. Nucl Med Biol 32: 485-493. 
Citation: Soendergaard M, Newton-Northup JR, Palmier MO, Deutscher SL (2011) Peptide Phage Display for Discovery of Novel Biomarkers for Imaging and Therapy of Cell Subpopulations in Ovarian Cancer. J Mol Biomark Diagn S2:004. doi:10.4172/2155-9929.S2-004

78. Miao Y, Hylarides M, Fisher DR, Shelton T, Moore H et al. (2005) Melanoma therapy via peptide-targeted \{alpha\}-radiation. Clin Cancer Res 11: 5616-5621.

79. Miao Y, Owen NK, Fisher DR, Hoffman TJ, Quinn TP (2005) Therapeutic efficacy of a 188Re-labeled alpha-melanocyte-stimulating hormone peptide analog in murine and human melanoma-bearing mouse models. J Nucl Med 46: 121-129.

80. Miao Y, Shelton T, Quinn TP (2007) Therapeutic efficacy of a 177Lu-labeled DOTA conjugated alpha-melanocyte-stimulating hormone peptide in a murine melanoma-bearing mouse model. Cancer Biother Radiopharm 22: 333-341.

81. Garvalov BK, Acker T (2011) Cancer stem cells: a new framework for the design of tumor therapies. J Mol Med 89: 95-107.

82. Deutscher SL (2010) Phage display in molecular imaging and diagnosis of cancer. Chem Rev 110: 3196-3211.

83. Goldenberg DM (2002) Targeted therapy of cancer with radiolabeled antibodies J Nucl Med 43: 693-713.

84. Behr TM, Gotthardt M, Barth A, Behe M (2001) Imaging tumors with peptidebased radioligands. Q J Nucl Med 45: 189-200.

85. Reubi JC (2003) Peptide receptors as molecular targets for cancer diagnosis and therapy. Endocr Rev 24: 389-427.

86. Behr TM, Sharkey RM, Juweid ME, Blumenthal RD, Dunn RM et al. (1995) Reduction of the renal uptake of radiolabeled monoclonal antibody fragments by cationic amino acids and their derivatives. Cancer Res 55: 3825-3834.

87. Rolleman EJ, Valkema R, de Jong M, Kooij PP, Krenning EP (2003) Safe and effective inhibition of renal uptake of radiolabelled octreotide by a combination of lysine and arginine. Eur J Nucl Med Mol Imaging 30: 9-15.

88. Garcia Garayoa E, Ruegg D, Blauenstein P, Zwimpfer M, Khan IU et al. (2007) Chemical and biological characterization of new $\operatorname{Re}(\mathrm{CO}) 3 /[99 \mathrm{mTc}](\mathrm{CO}) 3$ bombesin analogues. Nucl Med Biol 34: 17-28.

89. Racusen LC, Whelton A, Solez K (1985) Effects of lysine and other amino acids on kidney structure and function in the rat. Am J Pathol 120: 436-442.

90. Volkert W (1995) Ligand systems useful in designing high specific activity $99 \mathrm{mTc}$ or $186 \mathrm{Re} / 188 \mathrm{Re}$ radiopharmaceuticals. Technetium and Rhenium in Chemistry and Nuclear Medicine, (eds) M Nicolini, G Bandoli, U Mazzi, and SG Editorali. Padova, Italy

91. Garrison JC, Rold TL, Sieckman GL, Naz F, Sublett SV et al. (2008) Evaluation of the pharmacokinetic effects of various linking group using the $111 \mathrm{ln}$-DOTA$\mathrm{X}-\mathrm{BBN}(7-14) \mathrm{NH} 2$ structural paradigm in a prostate cancer model. Bioconjug Chem 19: 1803-1812.
92. Anderson CJ, Welch MJ (1999) Radiometal-labeled agents (non-technetium) for diagnostic imaging. Chem Rev 99: 2219-2234.

93. Quon A, Gambhir SS (2005) FDG-PET and beyond: molecular breast cancer imaging. J Clin Oncol 23: 1664-1673.

94. Kumar R (2007) PET/PET/CT in ovarian cancer. Ind J Med Paed Oncol 27.

95. Wadas TJ, Wong EH, Weisman GR, Anderson CJ (2010) Coordinating radiometals of copper, gallium, indium, yttrium, and zirconium for PET and SPECT imaging of disease. Chem Rev 110: 2858-2902.

96. Bakker WH, Krenning EP, Reubi JC, Breeman WA, Setyono-Han B et al (1991) In vivo application of [111ln-DTPA-D-Phe1]-octreotide for detection of somatostatin receptor-positive tumors in rats. Life Sci 49: 1593-1601.

97. McQuade P, Miao Y, Yoo J, Quinn TP, Welch MJ et al. (2005) Imaging of melanoma using 64Cu- and 86Y-DOTA-ReCCMSH(Arg11), a cyclized peptide analogue of alpha-MSH. J Med Chem 48: 2985-2992.

98. Wei L, Zhang X, Gallazzi F, Miao Y, Jin X et al. (2009) Melanoma imaging using (111)In-, (86)Y- and (68)Ga-labeled CHX-A"-Re(Arg11)CCMSH. Nucl Med Bio 36: $345-354$

99. Deutscher SL, Figueroa SD, Kumar SR (2009) In-labeled KCCYSL peptide as an imaging probe for ErbB-2-expressing ovarian carcinomas. J Labelled Comp Radiopharm 52: 583-590

100. Newton-Northup JR, Figueroa SD, Deutscher SL (2011) Streamlined in vivo selection and screening of human prostate carcinoma avid phage particles for development of peptide based in vivo tumor imaging agents. Comb Chem High Throughput Screen 14: 9-21.

101. Kwekkeboom DJ, Mueller-Brand J, Paganelli G, Anthony LB, Pauwels S et al. (2005) Overview of results of peptide receptor radionuclide therapy with 3 radiolabeled somatostatin analogs. J Nucl Med 46 Suppl 1: 62S-66S

102. Garkavij M, Nickel M, Sjogreen-Gleisner K, Ljungberg M, Ohlsson T et al. (2010) 177Lu-[DOTA0,Tyr3] octreotate therapy in patients with disseminated neuroendocrine tumors: Analysis of dosimetry with impact on future therapeutic strategy. Cancer 116: 1084-1092.

103. Gomes AF, Gozzo FC (2010) Chemical cross-linking with a diazirine photoactivatable cross-linker investigated by MALDI- and ESI-MS/MS. J Mass Spectrom 45: 892-899.

104. Kelly KA, Bardeesy N, Anbazhagan R, Gurumurthy S, Berger J et al. (2008) Targeted Nanoparticles for Imaging Incipient Pancreatic Ductal Adenocarcinoma. PLoS Med 5: e85. 